\title{
Alimentary System is Directly Attacked by SARS- COV-2 and Further Prevents Immune Dysregulation Caused by COVID-19
}

\section{Sai Chen}

West China Hospital, Sichuan University

Jing Zhou

West China Hospital, Sichuan University

Xiaoqi Ou UG

West China Hospital, Sichuan University

Wei Cheng

West China Hospital, Sichuan University

Yun Qin

West China Hospital, Sichuan University

Yingqiang Guo

West China Hospital, Sichuan University

Yunhan Jiang ( $\nabla$ cs19900512@sina.com)

West China Hospital, Sichuan University https://orcid.org/0000-0003-2759-2328

\section{Research}

Keywords: Severe acute respiratory syndrome coronavirus 2 (SARS-CoV-2), Coronavirus Disease 2019 (COVID-19), Alimentary system, Immune dysregulation, Bioinformatic analysis

Posted Date: September 18th, 2020

DOl: https://doi.org/10.21203/rs.3.rs-56005/v2

License: (c) (i) This work is licensed under a Creative Commons Attribution 4.0 International License.

Read Full License

Version of Record: A version of this preprint was published at International Journal of Clinical Practice on December 31st, 2020. See the published version at https://doi.org/10.1111/ijcp.13893. 


\section{Abstract}

Background. SARS-COV-2 causes digestive system symptom, the effect of which remains equivocal.

Methods. Patients with COVID-19 were classified into 4 groups according to symptom. The study traced the onset and duration of symptoms, compared laboratory examinations and conducted bioinformatic analysis. Immune indices were further analyzed.

Results. By March 16, 25 patients with COVID-19 and 13 with suspect COVID-19 were admitted to West China Hospital, Sichuan University. Digestive system symptom group had the highest level of ESR $(\mathrm{mm} / \mathrm{h}$, $P \otimes 0.0001)$, serum ferritin ( $\mathrm{ng} / \mathrm{ml}, P \otimes 0.0001)$, hepatic enzymes $(P \otimes 0.05)$, and retentive lymphocyte count/percentage $(P \otimes 0.05)$ and its subsets $(P \otimes 0.05)$. Combined group (respiratory combined with subsequent digestive system symptom) had the highest level of IL-6 (pg/ml, $P=0.0046), \mathrm{CRP}(\mathrm{mg} / \mathrm{L}$, $P=0.0004)$ and moderate lymphocyte depletion. Respiratory system symptom and asymptomatic groups suffered the most from lymphocyte depletion ( $P \otimes 0.05)$. Bioinformatic analysis indicated co-expression of binding related proteins of SARS-COV-2 (ACE2, TMPRSS2 and Furin) in small intestine. CD147 was extensively expressed in alimentary tract. CTSL, PIKfyve, TPC2 and CTSB could be detected with $\geq$ moderate expressions in a variety of organs including alimentary system.

Conclusions. Alimentary system is directly attacked by SARS-COV-2 other than hyperinflammation and immune dysregulation. Involvement of alimentary system might further protect mild and moderate cases from lymphocyte depletion caused by COVID-19.

\section{Introduction}

Since December 2019, the severe acute respiratory syndrome coronavirus 2 (SARS-CoV-2) of unknown origin was identified to cause pneumonia in about $20 \%$ of infective patients(1). Patients generally develop respiratory system symptom, with digestive system symptom being far from unique, ranging from $1 \%-50.5 \%(2)$. However, the effects of digestive system symptom were equivocally documented. Several studies concluded that patients with digestive system symptom were clinically severer(3-5), whereas a case-control study by Nobel YR et al. drew a nearly opposite conclusion that patients with digestive system symptom had a lower rate of ICU stay and mortality(6). A large cohort published in the New England Journal of Medicine also echoed that mortality was low in digestive system symptom group(7). The main limitations of these initial reports were: (a) only reported onset of digestive system symptom in the medical history with ignorance of specific course tracing; (b) lacked detailed grouping and definition of participants.

Emerging evidences suggested that alimentary injury probably resulted from direct virus infection. Initial results demonstrated existence of virus RNA in stool, although live virus could be hardly detected in it except two cases reported by Xiao F et al(8). Subsequently, quite a number of studies succeeded in identifying viral related inflammatory changes and entry proteins (ACE2, TMPRSS2 and Furin) (9-11) in alimentary system. Lamers MM et al. used human intestinal organoids to demonstrate in vitro that SARS- 
CoV-2 replicates readily in the gut enterocyte, and produced large amounts of infective virus particles in the gut(12). However, that digestive injury was caused by direct attack from the virus has been challenged by the phenomenon that digestive system symptom did not correlate with RNA detection in stool $(8,13)$. Furthermore, a recent study found that Faecal calprotectin (FCP), a widespread and sensitive marker for intestinal inflammation, was significantly associated with digestive system symptom in patients with COVID-19(14). Thus, it seems more reasonable that digestive symptom was a result of inflammation. Whether this inflammation was directly caused by the virus or by systemic inflammation still needs to be determined.

Researches have established angiotensin I converting enzyme 2 (ACE2) as the primary viral host receptor of SARS-COV-2, with CD147 recently having been discovered as another host receptor(15). Several proteins are critical for SARS-COV-2 entry into human cells. TMPRSS2 and Furin have been found essential to assist membrane fusion after the binding process $(9,10)$. After binding and membrane fusion, endocytosis is the primary process for SARS-COV-2 entry(16). Studies confirmed that PIKfyve, TPC2, Cathepsin L (CTSL) and Cathepsin B (CTSB) are critical for SARS-CoV-2 entry into human cells $(17,18)$. Thus, a wide protein expression profile: ACE2, TMPRSS2, Furin, CD147, CTSL, PIKfyve, TPC2, and CTSB better signals direct infiltration of SARS-COV-2 into human cells in vivo than pure detection of ACE2, TMPRSS2 and Furin.

In this study, we aimed to determine the relationship between digestive system symptom and COVID-19 through specific tracing of every patient, and explored another indirect evidence of SARS-COV-2 attacking our alimentary system using bioinformatical analysis.

\section{Methods}

\section{STUDY POPULATION}

The study enrolled patients with COVID-19 and suspect COVID-19 who underwent quarantine and received treatment in West China Hospital, Sichuan University from Jan 22 to March 16, 2020. The 25 patients with COVID-19 [mean age, 45.52 years (19-81)], 11 female and 14 male) were diagnosed according to the criteria issued by the National Health and Health Commission of China [Diagnosis and Treatment Guidelines for 2019 Novel Coronavirus Pneumonia (Trial Version 7)](19). All patients were strictly screened for history of epidemiology, clinical manifestations, blood examinations, radiographic presentations and confirmed by real-time PCR test. We divided the patients into 4 subgroups based on major clinical signs: 3 in digestive system symptom group, 14 in respiratory system symptom group, 4 in combined group and 4 in asymptomatic group.

\section{STUDY DESIGN}


This retrospective study specifically traced epidemiology history and clinical presentations in detail. Patients with COVID-19 were divided into 4 subgroups according to symptom, and with suspect COVID-19 set as control group. We collected all demographics, laboratory investigations in a data collection form modified from the standard electronic medical records. Computed tomography (CT) was used to diagnose infection in the lungs. CT findings and pulmonary inflammation index (PII) were scored by two experienced radiologists and inconsistency was solved by specific discussion between them until consistency was achieved. Severity was graded according to the Diagnosis and Treatment Guidelines for 2019 Novel Coronavirus Pneumonia (Trial Version 7)(19). Severity of illness scores (MuLBSTA, CURB-65 and PSI grading) were completed by resident physicians. Bioinformatic analysis was performed for expressions of ACE2, CD147, TMPRSS2, Cathepsin L, Cathepsin B, PIKfyve and TPC2 in different tissues and organs. Correlation analysis between symptom and location with SARS-Cov-2 positive was performed.

The study was approved by the Ethics Committee of West China Hospital and strictly followed the Declaration of Helsinki. Since this was a retrospective study, the committee waived the need for written consent of patients.

\section{BIOINFORMATIC ANALYSIS}

We gained bioinformatic data from the "TISSUE" units of "THE HUMAN PROTEIN ATLAS" (http://www.proteinatlas.org/) to analyze mRNA and protein expression profiles in various human tissues(20). The mRNA expression were extracted from GTEx dataset and demonstrated in reference to the normalized consensus dataset(21). "The PROTEIN EXPRESSION SUMMARY" category was chosen for protein expression scores.

\section{STATISTICAL ANALYSIS}

All data were tested for normality and homogeneity of variance. Continuous variables were presented as mean \pm standard deviation (SD) or median with interquartile range (IQR), and were analyzed by Student-t test or Wilcoxon signed rank test respectively. Categorical variables were described in number (\%) and compared by Chi-square test or Fisher's exact test according to the number of events. Correlation was analyzed by univariate and multivariate logistic regression. $P<0.05$ was set as the statistically significant threshold value. All analyses were conducted by SPSS 23.0 (SPSS inc., Chicago, IL, USA) statistical software.

\section{Results}

\section{BASELINE CHARACTERISTICS}

A total of 25 patients diagnosed as COVID-19 and 13 suspected cases were enrolled between Jan 23 and March 16, 2020. The mean age of COVID-19 group was $45.52 \pm 16.99$ (11 females) with comparison to 
$35.69 \pm 10.89$ ( 6 females) in suspect COVID-19 group ( $P=0.0433$ ). More than half of the COVID-19 patients $(14,56 \%)$ came from or had been to Wuhan recently (first generation). COVID-19 patients were classified into 4 groups based on the severity of the disease in strict accordance with the Diagnosis and Treatment Guidelines for 2019 Novel Coronavirus Pneumonia (Trial Version 7): 4 (16\%) mild, 17 (68\%) moderate, $3(12 \%)$ severe and 1 (4\%) critical. One patient (80-year-old, female, 4\%) died due to respiratory failure at the $6^{\text {th }}$ day after admission. A majority of the COVID-19 patients $(19,76 \%)$ had underlying diseases: 7 (28\%) hypertension, $2(8 \%)$ cardiovascular disease, 2 (8\%) diabetes, 2 (8\%) chronic obstructive pulmonary disease (COPD), 5 (20\%) chronic liver disease and 1 (4\%) hepatitis B virus (HBV) carrier. Diverse clinical presentations could be observed among COVID-19 patients at onset and on admission, albeit respiratory system symptom being the most widely. During hospitalization, digestive (7, 28\%), neuromuscular $(6,24 \%)$ and cardiovascular $(4,16 \%)$ symptoms have also emerged and occupied a certain proportion. These data and other basic characteristics were presented in Supplemental Table 1.

\section{CLINICAL CHRACTERISTICS}

Patients were divided into 4 groups according to symptom: 3 (12\%) in digestive system symptom group, $14(56 \%)$ in respiratory system symptom group, 4 (16\%) in combined group and $4(16 \%)$ in asymptomatic group. Baseline and clinical characteristics were summarized respectively. Digestive system symptom included diarrhea, nausea and vomiting. All 4 patients in combined group reported respiratory system symptom first, and then digestive system symptom emerged within 48 hours prior to admission. For each patient, their symptom persisted on admission. Nearly all baseline characteristics did not differ in the 4 groups, neither did clinical characteristics except for length of stay (IOS), where the digestive system symptom group reported the longest (Supplemental Table 2).

\section{LABORATORY EXAMINATIONS AND CT SCANS}

Clinical examinations on admission to hospital (Table 1 and Figure 1 ) were analyzed. For blood routine examination, lymphocyte (LYM) count $\left(x 10^{9} / \mathrm{L}, P=0.0101\right)$ and percentage $(\%, P=0.0033)$ typically remained near the normal range in digestive system symptom group, in comparison with significant reductions in other groups, which indicated unaffected systemic immunity in this group. Not surprisingly, digestive system symptom group suffered the most from alimentary injury, as 3 liver function indexes (alanine aminotransferase [ALT, U/L, $P \otimes 0.0001]$, alkaline phosphatase [ALP, U/L, $P=0.0167$ ] and $Y^{-}$ Glutamyl transpeptidase [GGT, U/L, $P=0.0018]$ ) increased significantly. Two infection related biomarkers, erythrocyte sedimentation rate (ESR, $\mathrm{mm} / \mathrm{h}, P \otimes 0.0001)$ and serum ferritin $(\mathrm{ng} / \mathrm{ml}, P \otimes 0.0001)$ had the highest level in this group. ESR generally points to bacterial infection. We believed that intestinal flora being interrupted by SARS-COV-2 could not be excluded, as could be observed in other reports $(22,23)$. Considering the prevalent liver damage in digestive system symptom group, elevation in serum ferritin could also be interpreted as affected liver function. Other inflammatory factors were not notably high in this group. 
Interleukin-6 (IL-6, pg/ml, $P=0.0046$ ) and C-reaction protein (CRP, $\mathrm{mg} / \mathrm{L}, P=0.0004$ ) were remarkably elevated in combined group, implying a different infective pattern in combined group from other groups. We emphasized on subsets of LYM cell count and percentage, and reported that CD3+ cell count $\left(10^{6} / \mathrm{L}\right.$, $P=0.0011), C D 3+$ cell percentage $(\%, P=0.0014)$ and $C D 8+$ cell count $\left(10^{6} / L, P=0.0021\right)$ were in the normal range in digestive system symptom group, as well as a steady CD $8+$ cell count $(\%, P=0.0013)$ in combined group, with contrast to significant reductions in respiratory system symptom group. CD4+/CD 8+ did not change much in digestive system symptom group compared to other groups $(P=0.0206)$. Nearly all laboratory examinations were similar in asymptomatic group to those in respiratory system symptom group, including immune indices (LYM and its subsets), with a few indicators being less severe in asymptomatic group. All these data did not support obvious immune dysregulation in digestive system symptom group, while it seemed the most depressed in the respiratory system symptom and asymptomatic group, and moderately disturbed in combined group. What needs to be noted, however, is that the 4 patients in the combined group could first be categorized as the respiratory system symptom group. Then, digestive system symptom emerged within 48 hours prior to admission and they were grouped into combined symptom. The subsequent digestive system symptom in combined group, which signaled an emerging local inflammation(14), as evidenced by elevated IL-6 and CRP in our study, probably limited immunodepression caused by pneumonia.

Some additional manifestations could be noticed. More frequent proteinuria $(P=0.0003)$ could be observed in digestive system symptom group, being mildly positive. Glucose ( $\mathrm{mmol} / \mathrm{L}, P=0.0152)$ did not seem to be affected in digestive system symptom group, as it only remained in the normal range in digestive system symptom and asymptomatic group. Troponin $\mathrm{T}(\mathrm{ng} / \mathrm{L}, P=0.0015)$ differed but remained normal among all groups (Supplemental Figure 1).

High-resolution computed tomography (HRCT) of the patients were read by the radiologists who recorded CT findings for each pulmonary lobe and then gave the total CT scores. Scores were not significantly different among the 4 groups. All patients showed signs of pneumonia on CT scans, although only respiratory system symptom and combined groups reported respiratory system symptom. Different evaluation scores were used for severity of illness, and no difference was found among MuLBSTA, CURB65, PSI grading and PII (Table 1).

\section{BIOINFORMATIC ANALYSIS}

In order to explore the reason why alimentary system was affected in COVID-19, especially in view of immune response being hardly dysregulated in digestive system symptom group than that in other groups, we attempted to investigate whether this phenomenon could be a result of direct infiltration of SARS-COV-2 through a combination of bioinformatic and clinical analysis. As is known that SARS-COV-2 could be detected in various tissues, we obtained bioinformatic data from the "TISSUE" units of "THE HUMAN PROTEIN ATLAS" (http://www.proteinatlas.org/) to analyze mRNA and protein expression profiles in various human tissues(20). Figure 2 summarized tissue-specific expressions of binding and endocytosis proteins of SARS-COV-2. The main binding protein of SARS-COV-2, ACE2, displayed high 
expressions of protein in kidney, small intestine and testis, and mild expression in adrenal gland and colon. It's worth noting that the mRNA expression in small intestine was also the highest. Another protein, CD147, which was found to be a binding protein of SARS-COV-2 recently, showed $\geq$ moderate expressions in the digestive tract (colon, stomach and esophagus and small intestine).

Several proteins assist the binding and endocytic process of SARS-COV-2. Moderate expression of TMPRSS2 existed in pancreas, salivary gland and small intestine. One of endocytosis proteins of SARSCOV-2, Cathepsin L (CTSL), exhibited moderate expression in liver, and mild expressions in colon, pancreas and salivary gland. We also found 3 endocytosis proteins (PIKfyve, TPC2 and CTSB) and 1 binding-related protein (Furin) that were widely expressed in different tissues (Figure 3). The results revealed ACE2, TMPRSS2 and Furin were co-expressed in small intestine, which strongly suggested small intestine being a major target of SARS-COV-2. Other binding and endocytosis proteins were widely expressed in alimentary system, small intestine included.

We believed that digestive system symptoms were more caused by direct infiltration of SARS-COV-2 into alimentary tract than subject to hyperinflammation or immune dysregulation brought by pneumonia based on findings above: (a) All necessary virus entry and endocytosis proteins could be found in alimentary system through bioinformatic analysis; (b) Re-elevation of IL- 6 and CRP in combined group might signal an acute "reinfection" in alimentary tract by the virus; (c) Appearance of digestive system symptom seemed to combat immune dysregulation, rather than be caused by it.

\section{CORRELATION BETWEEN SYMPTOM AND VIRUS LOCATION}

We continued to determine whether the location of SARS-COV-2 positive was associated with symptom (Supplemental Table 3). Nasal and throat swab were sensitive enough that the virus could be detected positive regardless of time and symptom. SARS-COV-2 RNA was hardly found in urine, even with proteinuria being found in digestive system symptom group and all SARS-COV-2 entry proteins being expressed in the kidney (Figure 2 and 3). Detection of SARS-COV-2 for cerebrospinal fluid (CSF) was conducted only once and turned out negative. Other locations (sputum, bronchoalveolar lavage fluid, stool and blood) of SARS-COV-2 were not significantly correlated with symptom $(P=0.5281,0.3865$, 0.8454 and 0.5488 respectively).

\section{Discussion}

The current study explored the role of digestive system symptom in patients with COVID-19 in a small cohort. We proved in an indirect way that digestive injury could be more likely resulted from direct infiltration of SARS-COV-2 than hyperinflammation and immune dysregulation brought by pneumonia. Furthermore, we suggested that involvement of alimentary system may even protect patients from immune dysregulation by COVID-19.

Researches on gastrointestinal symptoms for COVID-19 have been ambiguously reported, which was quite different from respiratory system symptom with nearly consistent results. This phenomenon 
suggested that digestive system symptom might be more complex than expected. We reviewed the reports on gastrointestinal symptoms for COVID-19, and found most of the researches were crosssectional and scarcely traced the onset, duration and disappearance of the symptoms. Digestive system symptom might have already disappeared on admission or merely appeared after admission. However, patients were all labeled "a history of digestive system symptom" and blood samples were mostly collected on admission. In our study, when patients were enrolled, we found that 4 patients with combined symptom had respiratory system symptom first, and then digestive system symptom just appeared within 48 hours prior to admission. For each patient in each group, their symptom still persisted on admission.

SARS-COV-2 could be found in stool, and even remained positive after nasal, throat and sputum swabs turned negative. Patients were allowed discharge after all tests turned negative, and digestive system symptom group usually had the longest IOS $(24,25)$. However, the clinical importance of continued presence of RNA in the stool is uncertain, since no apparent risk events occurred(5), as was also observed in our study. Inflammatory and immune indexes except the ESR (might reflect bacterial infection after alteration of intestinal flora) did not significantly alter in digestive system symptom, and this group suffered the least from immune dysregulation. Serum ferritin, ALT, AST, ALP, GGT was the highest in digestive system symptom group. Studies have proved that the major functional binding receptor ACE2 has rather limited expressions in hepatocytes and cholangiocytes(11), which was against liver as a primary SARS-COV-2 target. That gastrointestinal injury itself can cause an increase in liver enzymes could not be ruled out in this situation(23). Since every patient was identified pneumonia through CT scans, and immune dysregulation existed even in asymptomatic patients, it seemed that patients with gastrointestinal injury were against that immune dysregulation.

Researches have established ACE2 as the major binding receptor of SARS-COV-2. Given that SARS-COV-2 was transmitted by droplets and there was a widespread expression of ACE2 on AT2 cells in the lung, it was not difficult to understand why pneumonia was the dominant manifestation. It's worth noting that the lung is a "frothy" organ and ACE2 is merely expressed on AT2 cells, protein and mRNA expressions of ACE2 might seem quite trivial compared to those expressed in solid organs. Our study also found trial mRNA and bare protein of AT2 in the lung, similar to other studies $(10,11)$. We did, however, assume that the bioinformatic analysis was more applicable to other solid organs.

SARS-COV-2 entry into host cells is regulated by the spike (S) glycoprotein that forms homotrimers protruding out from the viral surface(26). $S$ consists of $S 1$ and $S 2$ subunits accounting for binding to the receptor and fusion between the viral and cellular membranes, respectively(27). $S$ is further cleaved by host proteases, a process necessary to promote virus-cell fusion $(27,28)$. Recently, Furin and TMPRSS2 were identified as proteases assisting SARS-COV-2 infection by a number of studies $(9,10)$. Studies have suggested co-expression of TMPRSS2 and Furin with ACE2 could be more meaningful as an indicator of SARS-COV-2 target $(9,10,29)$. We found that small intestine might be an important target of SARS-COV-2 since a combination of ACE2, TMPRSS2 and Furin proteins could be detected in small intestine. Other endocytosis proteins, PIKfyve, TPC2, combined with the protease CBSL, could also be detected in small 
intestine. CD147 protein was found in colon, esophagus, small intestine and stomach. These results suggested that small intestine was potentially the major target.

In order to further clarify whether involvement of alimentary system could provide protection from SARSCOV-2, we systematically compared the clinical results and laboratory examinations on admission, and combined group attracted our attention. Four patients suffering respiratory system symptom gradually developed digestive system symptom, and they were grouped into combined group. However, many indexes differed them from those who purely had digestive system symptoms and those who purely had respiratory system symptom. Firstly, they had remarkably higher levels of CRP and IL-6, which indicated an acute infection accompanied by robust immune response. Lin L. et al demonstrated that viraemia following lung infection was rare(30), consistent with our study where only one patient was detected with viraemia. They reported that infection in lung may lead to a secondary attack on ACE2 target organs such as the kidney and the intestine(30). Thus, elevated of IL-6 and CRP in combined group might be attributed to a subsequent "acute reinfection" through oral route (swallowing upper respiratory secretion etc.), which agreed with the idea that alimentary could be directly attacked by SARS-COV-2. Secondly, they did not develop liver damage, which further explained a delayed or slighter infection in alimentary system. Thirdly, the immunodepression was somewhere between the respiratory group and digestive group. To sum up, the emergence of digestive system symptom seemed to salvage the immune dysregulation to a certain extent, which was echoed by what was observed in digestive system symptom group.

We hypothesized that the involvement of alimentary system may provide protection through competitive inhibition and anti-inflammatory mechanism. A soluble form of ACE2 that lacks the membrane anchor and partly circulates in blood can be produced by proteolytic cleavage(31). It has been proposed that the soluble form of ACE2 competitively inhibits the cellular full-length ACE2 protein so that SARS-COV is sequestrated(32), limiting infective progression and reducing susceptibility to further infection(33). Interestingly, the cleavage of ACE2 into the soluble form is mediated by the ADAM17, a TNF-a convertase upregulated in patients with gastrointestinal injury or inflammation(34). Moreover, ACE2 has been demonstrated to participate in reninangiotensin-aldosterone system (RAAS) that includes the classical ACE2/Ang 1-7/MAS-1 receptor (MAS1-R)(35). Studies have suggested that ACE2/MasR system plays a critical role in numerous anti-inflammatory pathways regulating tissue protection(36). However, with limited number of patients in each group and lack of experimental designs, other studies were warranted to confirm this observation in our study.

\section{LIMITATIONS}

Firstly, the limited number of patients may weaken reliabilities and conclusions. Secondly, lack of experimental results requires further confirmation of the observations. Finally, more inflammatory and immune indexes are warranted.

\section{Conclusions}


The present study is a single-center study that explores the reason and effect of digestive involvement in COVID-19. As follows are the major findings in our study: 1) Alimentary system is directly attacked by SARS-COV-2 other than hyperinflammation and immune dysregulation. 2) Involvement of alimentary system might further protect mild and moderate cases from lymphocyte depletion caused by COVID-19.

\section{Declarations}

The study was approved by the Ethics Committee of West China Hospital and strictly followed the Declaration of Helsinki. Since this was a retrospective study, the committee waived the need for written consent of patients and the research was allowed for publication. The data and materials were available, and we declare that we have no conflict of interest. This manuscript was supported by Post-Doctor Research Project, West China Hospital, Sichuan University (No.2020HXBH043) and Science And Technology Project of The Health Planning Committee of Sichuan (No.20PJ001). Doctor Sai Chen was responsible for the writing of the manuscript and funding, Miss Jing Zhou and Xiaoqi Ou were responsible for data acquisition and software, Doctor Wei Cheng and Yun Qin were responsible for CT reading and data analysis, Doctor Yingqiang Guo was responsible for clinical recordings, and Doctor Yunhan Jiang was responsible for the design and supervision of the work. We had special acknowledgements to Doctor Yingqiang Guo for his professional opinions.

Funding: This manuscript was supported by Post-Doctor Research Project, West China Hospital, Sichuan University (No.2020HXBH043) and Science And Technology Project of The Health Planning Committee of Sichuan (No.20PJ001).

\section{References}

1. Berlin DA, Gulick RM, and Martinez FJ. Severe Covid-19. N Engl J Med. 2020.

2. Huang C, Wang Y, Li X, Ren L, Zhao J, Hu Y, Zhang L, Fan G, Xu J, Gu X, et al. Clinical features of patients infected with 2019 novel coronavirus in Wuhan, China. Lancet. 2020;395(10223):497-506.

3. Wang D, Hu B, Hu C, Zhu F, Liu X, Zhang J, Wang B, Xiang H, Cheng Z, Xiong Y, et al. Clinical Characteristics of 138 Hospitalized Patients With 2019 Novel Coronavirus-Infected Pneumonia in Wuhan, China. JAMA. 2020.

4. Jin X, Lian JS, Hu JH, Gao J, Zheng L, Zhang YM, Hao SR, Jia HY, Cai H, Zhang XL, et al. Epidemiological, clinical and virological characteristics of 74 cases of coronavirus-infected disease 2019 (COVID-19) with gastrointestinal symptoms. Gut. 2020;69(6):1002-9.

5. Cheung KS, Hung IFN, Chan PPY, Lung KC, Tso E, Liu R, Ng YY, Chu MY, Chung TWH, Tam AR, et al. Gastrointestinal Manifestations of SARS-CoV-2 Infection and Virus Load in Fecal Samples From a Hong Kong Cohort: Systematic Review and Meta-analysis. Gastroenterology. 2020;159(1):81-95.

6. Nobel YR, Phipps M, Zucker J, Lebwohl B, Wang TC, Sobieszczyk ME, and Freedberg DE. Gastrointestinal Symptoms and COVID-19: Case-Control Study from the United States. Gastroenterology. 2020. 
7. Beattie RM, Ashton JJ, and Penman ID. COVID-19 and the gastrointestinal tract: emerging clinical data. Frontline Gastroenterol. 2020;11(4):290-2.

8. Xiao F, Tang M, Zheng X, Liu Y, Li X, and Shan H. Evidence for Gastrointestinal Infection of SARSCoV-2. Gastroenterology. 2020;158(6):1831-3 e3.

9. Walls AC, Park YJ, Tortorici MA, Wall A, McGuire AT, and Veesler D. Structure, Function, and Antigenicity of the SARS-CoV-2 Spike Glycoprotein. Cell. 2020;181(2):281-92 e6.

10. Hoffmann M, Kleine-Weber H, Schroeder S, Kruger N, Herrler T, Erichsen S, Schiergens TS, Herrler G, Wu NH, Nitsche A, et al. SARS-CoV-2 Cell Entry Depends on ACE2 and TMPRSS2 and Is Blocked by a Clinically Proven Protease Inhibitor. Cell. 2020;181(2):271-80 e8.

11. Liu X, Chen Y, Tang W, Zhang L, Chen W, Yan Z, Yuan P, Yang M, Kong S, Yan L, et al. Single-cell transcriptome analysis of the novel coronavirus (SARS-CoV-2) associated gene ACE2 expression in normal and non-obstructive azoospermia (NOA) human male testes. Sci China Life Sci. 2020.

12. Lamers MM, Beumer J, van der Vaart J, Knoops K, Puschhof J, Breugem TI, Ravelli RBG, Paul van Schayck J, Mykytyn AZ, Duimel HQ, et al. SARS-CoV-2 productively infects human gut enterocytes. Science. 2020;369(6499):50-4.

13. Lin L, Jiang X, Zhang Z, Huang S, Zhang Z, Fang Z, Gu Z, Gao L, Shi H, Mai L, et al. Gastrointestinal symptoms of 95 cases with SARS-CoV-2 infection. Gut. 2020;69(6):997-1001.

14. Effenberger M, Grabherr F, Mayr L, Schwaerzler J, Nairz M, Seifert M, Hilbe R, Seiwald S, Scholl-Buergi $S$, Fritsche G, et al. Faecal calprotectin indicates intestinal inflammation in COVID-19. Gut. 2020;69(8):1543-4.

15. Ulrich H, and Pillat MM. CD147 as a Target for COVID-19 Treatment: Suggested Effects of Azithromycin and Stem Cell Engagement. Stem Cell Rev Rep. 2020.

16. Glebov 00. Understanding SARS-CoV-2 endocytosis for COVID-19 drug repurposing. FEBS J. 2020.

17. Ou X, Liu Y, Lei X, Li P, Mi D, Ren L, Guo L, Guo R, Chen T, Hu J, et al. Characterization of spike glycoprotein of SARS-CoV-2 on virus entry and its immune cross-reactivity with SARS-CoV. Nat Commun. 2020;11(1):1620.

18. Smieszek SP, Przychodzen BP, and Polymeropoulos MH. Amantadine disrupts lysosomal gene expression: A hypothesis for COVID19 treatment. Int J Antimicrob Agents. 2020:106004.

19. China NHaHCo. Diagnosis and treatment guidelines for 2019 novel coronavirus pneumonia. 2020.

20. Uhlen M, Fagerberg L, Hallstrom BM, Lindskog C, Oksvold P, Mardinoglu A, Sivertsson A, Kampf C, Sjostedt E, Asplund A, et al. Proteomics. Tissue-based map of the human proteome. Science. 2015;347(6220):1260419.

21. Carithers LJ, and Moore HM. The Genotype-Tissue Expression (GTEx) Project. Biopreserv Biobank. 2015;13(5):307-8.

22. Brenner EJ, Ungaro RC, Gearry RB, Kaplan GG, Kissous-Hunt M, Lewis JD, Ng SC, Rahier JF, Reinisch W, Ruemmele FM, et al. Corticosteroids, But Not TNF Antagonists, Are Associated With Adverse 
COVID-19 Outcomes in Patients With Inflammatory Bowel Diseases: Results From an International Registry. Gastroenterology. 2020.

23. Pan L, Mu M, Yang P, Sun Y, Wang R, Yan J, Li P, Hu B, Wang J, Hu C, et al. Clinical Characteristics of COVID-19 Patients With Digestive Symptoms in Hubei, China: A Descriptive, Cross-Sectional, Multicenter Study. Am J Gastroenterol. 2020;115(5):766-73.

24. Pirola CJ, and Sookoian S. COVID-19 and ACE2 in the liver and gastrointestinal tract: Putative biological explanations of sexual dimorphism. Gastroenterology. 2020.

25. Zhou Z, Zhao N, Shu Y, Han S, Chen B, and Shu X. Effect of Gastrointestinal Symptoms on Patients Infected With Coronavirus Disease 2019. Gastroenterology. 2020.

26. Tortorici MA, and Veesler D. Structural insights into coronavirus entry. Adv Virus Res. 2019;105(93116.

27. Walls AC, Xiong X, Park YJ, Tortorici MA, Snijder J, Quispe J, Cameroni E, Gopal R, Dai M, Lanzavecchia A, et al. Unexpected Receptor Functional Mimicry Elucidates Activation of Coronavirus Fusion. Cell. 2019;176(5):1026-39 e15.

28. Park YJ, Walls AC, Wang Z, Sauer MM, Li W, Tortorici MA, Bosch BJ, DiMaio F, and Veesler D. Structures of MERS-CoV spike glycoprotein in complex with sialoside attachment receptors. Nat Struct Mol Biol. 2019;26(12):1151-7.

29. Hirano T, and Murakami M. COVID-19: A New Virus, but a Familiar Receptor and Cytokine Release Syndrome. Immunity. 2020;52(5):731-3.

30. Lin L, Lu L, Cao W, and Li T. Hypothesis for potential pathogenesis of SARS-CoV-2 infection-a review of immune changes in patients with viral pneumonia. Emerg Microbes Infect. 2020;9(1):727-32.

31. Wysocki J, Ye M, Rodriguez E, Gonzalez-Pacheco FR, Barrios C, Evora K, Schuster M, Loibner H, Brosnihan KB, Ferrario CM, et al. Targeting the degradation of angiotensin II with recombinant angiotensin-converting enzyme 2: prevention of angiotensin II-dependent hypertension. Hypertension. 2010;55(1):90-8.

32. Ibrahim IM, Abdelmalek DH, Elshahat ME, and Elfiky AA. COVID-19 spike-host cell receptor GRP78 binding site prediction. $J$ Infect. 2020;80(5):554-62.

33. Batlle D, Wysocki J, and Satchell K. Soluble angiotensin-converting enzyme 2: a potential approach for coronavirus infection therapy? Clin Sci (Lond). 2020;134(5):543-5.

34. Wong E, Cohen T, Romi E, Levin M, Peleg Y, Arad U, Yaron A, Milla ME, and Sagi I. Harnessing the natural inhibitory domain to control TNFalpha Converting Enzyme (TACE) activity in vivo. Sci Rep. 2016;6(35598.

35. Zhang H, Penninger JM, Li Y, Zhong N, and Slutsky AS. Angiotensin-converting enzyme 2 (ACE2) as a SARS-CoV-2 receptor: molecular mechanisms and potential therapeutic target. Intensive Care Med. 2020;46(4):586-90.

36. Hashimoto T, Perlot T, Rehman A, Trichereau J, Ishiguro H, Paolino M, Sigl V, Hanada T, Hanada R, Lipinski S, et al. ACE2 links amino acid malnutrition to microbial ecology and intestinal inflammation. Nature. 2012;487(7408):477-81. 


\section{Description Of Supplementary Files}

Supplemental Fig. 1. Glucose and Troponin T differences in each group.

\section{Table}


Table 1. Clinical Indexes of COVID-19 Patients with Different Types of Symptom.

$\begin{array}{lllll}\text { Combined } & \text { Respiratory } & \text { Digestive } & \text { Asymptomatic } & P \\ \text { group }(n=4) & \text { system } & \text { system } & \text { group }(n=4) & \text { value } \\ \text { (mean } \pm \text { SD) } & \text { symptom group } & \text { symptom } & & \\ & (n=14) & \text { group }(n=3) & & \end{array}$

Blood routine

examination

\begin{tabular}{|c|c|c|c|c|c|}
\hline $\begin{array}{l}\text { WBC count } \\
\left(x 10^{9} / L\right)\end{array}$ & $6.67 \pm 2.61$ & $5.92 \pm 1.54$ & $5.03 \pm 1.00$ & $4.88 \pm 2.19$ & 0.5554 \\
\hline$>10.0$, No. $(\%)$ & 1 & 0 & 0 & 0 & 0.1405 \\
\hline$<4.0$, No. (\%) & 0 & 1 & 1 & 2 & 0.1277 \\
\hline $\begin{array}{l}\text { NEU count } \\
\left(\times 10^{9} / \mathrm{L}\right)\end{array}$ & $4.47 \pm 1.86$ & $4.10 \pm 1.42$ & $2.89 \pm 0.64$ & $3.23 \pm 2.08$ & 0.5233 \\
\hline $\begin{array}{l}\text { NEU percentage } \\
(\%)\end{array}$ & $66.65 \pm 5.63$ & $68.39 \pm 8.52$ & $57.23 \pm 1.65$ & $60.28 \pm 15.7$ & 0.2626 \\
\hline $\begin{array}{l}\text { LYM count } \\
\left(\times 10^{9} / \mathrm{L}\right)\end{array}$ & $1.46 \pm 0.23$ & $1.17 \pm 0.27$ & $1.7 \pm 0.09$ & $1.15 \pm 0.12$ & 0.0101 \\
\hline$\geq 1.0$, No. (\%) & 4 & 11 & 3 & 3 & 0.5974 \\
\hline $\begin{array}{l}\text { LYM percentage } \\
(\%)\end{array}$ & $23.88 \pm 3.26$ & $20.93 \pm 4.08$ & $31.4 \pm 0.98$ & $22.7 \pm 2.62$ & 0.0033 \\
\hline $\begin{array}{l}\text { MON count } \\
\left(x 10^{9} / \mathrm{L}\right)\end{array}$ & $0.61 \pm 0.24$ & $0.58 \pm 0.20$ & $0.52 \pm 0.06$ & $0.42 \pm 0.10$ & 0.4772 \\
\hline $\begin{array}{l}\text { MON percentage } \\
(\%)\end{array}$ & $9.3 \pm 2.32$ & $10.06 \pm 2.86$ & $10.5 \pm 1.22$ & $9.93 \pm 4.5$ & 0.9660 \\
\hline $\begin{array}{l}\text { PLT count } \\
\left(x 10^{9} / \mathrm{L}\right)\end{array}$ & $\begin{array}{l}235.25 \pm \\
59.82\end{array}$ & $203.21 \pm 49.85$ & $249.33 \pm 89.46$ & $\begin{array}{l}150.25 \pm \\
69.64\end{array}$ & 0.2118 \\
\hline $\begin{array}{l}\text { Eosinophils (x } \\
\left.10^{9} / \mathrm{L}\right)\end{array}$ & $0.02 \pm 0.01$ & $0.03 \pm 0.04$ & $0.03 \pm 0.02$ & $0.01 \pm 0.02$ & 0.7767 \\
\hline
\end{tabular}

$\begin{array}{llllll}\text { Eosinophil ratios } \quad 0.23 \pm 0.21 & 0.54 \pm 0.78 & 0.47 \pm 0.37 & 0.13 \pm 0.22 & 0.7033\end{array}$
$(\%)$

\begin{tabular}{llllll}
$\begin{array}{l}\text { Haemoglobin } \\
(\mathrm{g} / \mathrm{L})\end{array}$ & $140.5 \pm 8.73$ & $148.21 \pm 19.97$ & $132.33 \pm 25.9$ & $\begin{array}{l}139.75 \pm \\
14.25\end{array}$ & 0.5414 \\
\hline NLR & $3.42 \pm 1.34$ & $3.82 \pm 1.86$ & $1.83 \pm 0.1$ & $2.67 \pm 1.63$ & 0.2633 \\
\hline$>5$, No. (\%) & 1 & 2 & 0 & 1 & 0.7809 \\
\hline PLR & $\begin{array}{l}183.61 \pm \\
61.66\end{array}$ & $183.15 \pm 55.42$ & $155.42 \pm 37.11$ & $\begin{array}{l}124.94 \pm \\
54.26\end{array}$ & 0.2927 \\
& & & & &
\end{tabular}


Table 1. Clinical Indexes of COVID-19 Patients with Different Types of Symptom.

\begin{tabular}{|c|c|c|c|c|c|}
\hline > 200, No. (\%) & 1 & 5 & 1 & 1 & 0.9653 \\
\hline SII & $\begin{array}{l}778.64 \pm \\
276.96\end{array}$ & $764.1 \pm 371.6$ & $\begin{array}{l}460.01 \pm \\
174.23\end{array}$ & $\begin{array}{l}496.14 \pm \\
525.61\end{array}$ & 0.4116 \\
\hline$>500$, No. (\%) & 4 & 9 & 1 & 1 & 0.1269 \\
\hline \multicolumn{6}{|l|}{$\begin{array}{l}\text { Infection related } \\
\text { biomarkers }\end{array}$} \\
\hline РСТ (ng/ml) & $0.05 \pm 0.01$ & $0.04 \pm 0.01$ & $0.05 \pm 0$ & $0.06 \pm 0.02$ & 0.2380 \\
\hline IL-6 (pg/ml) & $26.08 \pm 19.23$ & $6.11 \pm 2.9$ & $6.88 \pm 3.37$ & $4.3 \pm 2.76$ & 0.0046 \\
\hline$\underset{(\%)}{\geq 7.0 \mathrm{pg} / \mathrm{ml} \text {, No. }}$ & 4 & 3 & 2 & 1 & 0.0258 \\
\hline CRP (mg/L) & $68.38 \pm 45.97$ & $9.63 \pm 6.19$ & $8.07 \pm 0.8$ & $3.54 \pm 2.78$ & 0.0004 \\
\hline$>8$ mg/L, No. (\%) & 4 & 5 & 1 & 1 & 0.1020 \\
\hline $\operatorname{ESR}(\mathrm{mm} / \mathrm{h})$ & $29.33 \pm 38.66$ & $40.75 \pm 14.58$ & $57 \pm 25.47$ & $23 \pm 8$ & $<.0001$ \\
\hline $\begin{array}{l}>20 \mathrm{~mm} / \mathrm{h}, \text { No. } \\
(\%)\end{array}$ & 1 & 13 & 3 & 1 & 0.0047 \\
\hline $\begin{array}{l}\text { Serum ferritin } \\
(\mathrm{ng} / \mathrm{ml})\end{array}$ & $312 \pm 66.72$ & $219.42 \pm 121.57$ & $844 \pm 23.37$ & $\begin{array}{l}256.5 \pm \\
110.36\end{array}$ & $\stackrel{<}{0.0001}$ \\
\hline
\end{tabular}

liver function

\begin{tabular}{|llllll}
\hline ALT (U/L) & $18.25 \pm 5.40$ & $26.79 \pm 6.43$ & $56.67 \pm 11.84$ & $23.50 \pm 4.50$ & $<$ \\
\hline$>40 \mathrm{U} / \mathrm{L}$ & 0 & 1 & 3 & 0 & 0.0001 \\
\hline AST (U/L) & $16.50 \pm 4.77$ & $20.14 \pm 7.12$ & $39.00 \pm 5.35$ & $21.25 \pm 2.49$ & 0.0010 \\
\hline$>40 \mathrm{U} / \mathrm{L}$ & 0 & 1 & 1 & 0 & 0.3441 \\
\hline Albumin (g/L) & $41.25 \pm 4.54$ & $44.23 \pm 3.15$ & $42.03 \pm 4.63$ & $42.45 \pm 2.96$ & 0.4208 \\
\hline TBIL (umol/L) & $15.18 \pm 4.11$ & $11.6 \pm 8.12$ & $12.67 \pm 5.12$ & $10.58 \pm 6.00$ & 0.7978 \\
\hline DBIL (umol/L) & $4.98 \pm 1.01$ & $4.03 \pm 2.46$ & $4.37 \pm 1.68$ & $4.48 \pm 3.02$ & 0.9062 \\
\hline ALP (U/L) & $64.25 \pm 3.96$ & $59.36 \pm 11.35$ & $80.67 \pm 4.19$ & $57.75 \pm 4.97$ & 0.0167 \\
\hline $\begin{array}{l}\text { GGT (U/L) } \\
\begin{array}{l}\text { myocardial injury } \\
\text { markers }\end{array}\end{array}$ & $16.50 \pm 3.57$ & $30.07 \pm 14.92$ & $59.67 \pm 16.82$ & $15.00 \pm 6.36$ & 0.0018 \\
\hline
\end{tabular}


Table 1. Clinical Indexes of COVID-19 Patients with Different Types of Symptom.

\begin{tabular}{|c|c|c|c|c|c|}
\hline LDH (U/L) & $\begin{array}{l}187.50 \pm \\
50.42\end{array}$ & $173.86 \pm 87.24$ & $171.33 \pm 30.88$ & $\begin{array}{l}214.75 \pm \\
14.04\end{array}$ & 0.8018 \\
\hline CK (U/L) & $65.75 \pm 21.55$ & $117.83 \pm 90.22$ & $78.33 \pm 32.19$ & $\begin{array}{l}158.25 \pm \\
77.12\end{array}$ & 0.3951 \\
\hline CK-MB (ng/mL) & $1.05 \pm 0.53$ & $0.99 \pm 0.51$ & $0.90 \pm 0.42$ & $0.90 \pm 0.14$ & 0.9602 \\
\hline $\begin{array}{l}\text { Myoglobin } \\
\text { (ng/mL) }\end{array}$ & $35.38 \pm 13.52$ & $33.73 \pm 22.80$ & $24.57 \pm 4.88$ & $27.90 \pm 3.07$ & 0.8223 \\
\hline Troponin T (ng/L) & $9.25 \pm 3.45$ & $4.78 \pm 2.21$ & $8.93 \pm 1.19$ & $3.80 \pm 0.50$ & 0.0015 \\
\hline a-HBDH (U/L) & $\begin{array}{l}151.00 \pm \\
28.85\end{array}$ & $138.43 \pm 51.10$ & $119.33 \pm 8.50$ & $\begin{array}{l}167.25 \pm \\
10.11\end{array}$ & 0.5123 \\
\hline \multicolumn{6}{|l|}{ kidney function } \\
\hline $\begin{array}{l}\text { Glucose } \\
(\mathrm{mmol} / \mathrm{L})\end{array}$ & $6.31 \pm 0.56$ & $7.38 \pm 1.36$ & $4.86 \pm 0.37$ & $5.88 \pm 0.38$ & 0.0152 \\
\hline BUN (mmol/L) & $4.90 \pm 0.95$ & $3.46 \pm 0.96$ & $4.40 \pm 0.83$ & $4.25 \pm 0.88$ & 0.0527 \\
\hline $\mathrm{Cr}(\mu \mathrm{mol} / \mathrm{L})$ & $83.75 \pm 19.04$ & $77.42 \pm 18.55$ & $71.33 \pm 8.01$ & $81.25 \pm 19.11$ & 0.8108 \\
\hline $\begin{array}{l}\text { eGFR } \\
(\mathrm{ml} / \mathrm{min} / 1.73 \mathrm{~m} 2)\end{array}$ & $82.18 \pm 24.16$ & $98.32 \pm 14.58$ & $98.32 \pm 12.37$ & $91.02 \pm 5.76$ & 0.3053 \\
\hline
\end{tabular}

Proteinuria (\%)

$\begin{array}{llllll}\text { Negative } & 2 & 14 & 0 & 4 & 0.0003 \\ + & 1 & 0 & 3 & 0 & \\ ++\sim+++ & 1 & 0 & 0 & 0\end{array}$

Hematuria (\%)

$\begin{array}{llllll}\text { Negative } & 2 & 13 & 2 & 4 & 0.2224 \\ + & 1 & 1 & 0 & 0 & \\ ++++++ & 1 & 0 & 1 & 0\end{array}$

coagulation

function

\begin{tabular}{llllll} 
PT (s) & $12.03 \pm 0.36$ & $11.03 \pm 0.57$ & $11.47 \pm 1.44$ & $11.20 \pm 0.10$ & 0.0796 \\
\hline APTT (s) & $32.53 \pm 3.34$ & $30.36 \pm 1.72$ & $29.87 \pm 3.00$ & $30.35 \pm 0.65$ & 0.2872 \\
\hline INR & $1.02 \pm 0.03$ & $0.94 \pm 0.06$ & $0.99 \pm 0.13$ & $0.95 \pm 0.02$ & 0.1584 \\
FIB (g/L) & $3.51 \pm 0.74$ & $3.64 \pm 0.94$ & $3.86 \pm 1.04$ & $3.01 \pm 0.11$ & 0.5519 \\
\hline
\end{tabular}


Table 1. Clinical Indexes of COVID-19 Patients with Different Types of Symptom.

\begin{tabular}{llllll}
$\begin{array}{l}\text { D-dimer }(\mathrm{mg} / \mathrm{L} \\
\text { FEU) }\end{array}$ & $0.3 \pm 0.18$ & $0.25 \pm 0.1$ & $1.52 \pm 1.78$ & $1.49 \pm 1.47$ & 0.2188 \\
\hline $\begin{array}{l}\text { Arterial blood gas } \\
\text { lactic acid }\end{array}$ & $0.94 \pm 0.22$ & $0.83 \pm 0.12$ & $0.98 \pm 0.20$ & $0.92 \pm 0.19$ & 0.3509 \\
\hline \begin{tabular}{l}
$\mathrm{mmol} / \mathrm{L})$ \\
\hline
\end{tabular} & & & & & \\
\hline
\end{tabular}

Electrolyte levels

\begin{tabular}{|c|c|c|c|c|c|}
\hline $\begin{array}{l}\text { Potassium } \\
(\mathrm{mmol} / \mathrm{L})\end{array}$ & $3.81 \pm 0.38$ & $3.78 \pm 0.34$ & $3.77 \pm 0.08$ & $4.23 \pm 0.39$ & 0.1520 \\
\hline Sodium (mmol/L) & $137.25 \pm 3.07$ & $138.01 \pm 5.62$ & $138.90 \pm 4.4$ & $139.65 \pm 0.85$ & 0.8932 \\
\hline $\begin{array}{l}\text { Serum Chlorine } \\
\text { (mmol/L) }\end{array}$ & $99.13 \pm 2.69$ & $100.00 \pm 4.21$ & $101.30 \pm 2.60$ & $102.60 \pm 1.80$ & 0.5214 \\
\hline $\begin{array}{l}\text { Calcium } \\
\text { (mmol/L) }\end{array}$ & $2.16 \pm 0.18$ & $2.22 \pm 0.08$ & $2.17 \pm 0.01$ & $2.26 \pm 0.18$ & 0.5859 \\
\hline \multicolumn{6}{|l|}{ cytokines } \\
\hline TNF-a (pg/ml) & $4.93 \pm 0.73$ & $6.08 \pm 1.97$ & $4.2 \pm 0.14$ & $4.63 \pm 0.72$ & 0.2051 \\
\hline \multicolumn{6}{|l|}{$\begin{array}{l}\text { Immunocyte } \\
\text { detection and } \\
\text { absolute count }\end{array}$} \\
\hline $\begin{array}{l}\text { CD3 + cell count } \\
\left(10^{6} / \mathrm{L}\right)\end{array}$ & $\begin{array}{l}1165 \pm \\
344.93\end{array}$ & $726.43 \pm 235.73$ & $\begin{array}{l}1475.33 \pm \\
352.88\end{array}$ & $710.5 \pm 43.59$ & 0.0011 \\
\hline $\begin{array}{l}\text { CD3 + cell count } \\
(\%)\end{array}$ & $73.33 \pm 3.26$ & $62.04 \pm 6.12$ & $72.97 \pm 4.29$ & $59.08 \pm 3.82$ & 0.0014 \\
\hline $\begin{array}{l}\text { CD } 4+\text { cell count } \\
\left(10^{6} / \mathrm{L}\right)\end{array}$ & $\begin{array}{l}400.00 \pm \\
219.34\end{array}$ & $546.88 \pm 251.91$ & $\begin{array}{l}653.33 \pm \\
174.81\end{array}$ & $\begin{array}{l}453.00 \pm \\
31.00\end{array}$ & 0.4383 \\
\hline $\begin{array}{l}\text { CD4 + cell count } \\
(\%)\end{array}$ & $29.05 \pm 6.90$ & $38.83 \pm 9.61$ & $35.30 \pm 2.76$ & $36.90 \pm 0.60$ & 0.2288 \\
\hline $\begin{array}{l}\text { CD8 + cell count } \\
\left(10^{6} / \mathrm{L}\right)\end{array}$ & $\begin{array}{l}358.50 \pm \\
97.29\end{array}$ & $252.50 \pm 87.93$ & $\begin{array}{l}578.33 \pm \\
220.38\end{array}$ & $\begin{array}{l}249.00 \pm \\
13.55\end{array}$ & 0.0021 \\
\hline $\begin{array}{l}\text { CD8 + cell count } \\
(\%)\end{array}$ & $31.65 \pm 8.94$ & $18.46 \pm 6.02$ & $30.23 \pm 1.64$ & $15.00 \pm 3.05$ & 0.0013 \\
\hline CD4+/CD8+ & $1.03 \pm 0.40$ & $2.56 \pm 1.13$ & $1.18 \pm 0.16$ & $2.90 \pm 0.88$ & 0.0206 \\
\hline B cell (\%) & $10.78 \pm 2.09$ & $12.19 \pm 3.67$ & $12.13 \pm 0.83$ & $13.08 \pm 4.42$ & 0.8481 \\
\hline $\begin{array}{l}\text { B cell count } \\
\left(10^{6} / \mathrm{L}\right)\end{array}$ & $\begin{array}{l}218.75 \pm \\
75.33\end{array}$ & $230.21 \pm 67.86$ & $260.67 \pm 57.62$ & $\begin{array}{l}280.33 \pm \\
17.21\end{array}$ & 0.6049 \\
\hline
\end{tabular}


Table 1. Clinical Indexes of COVID-19 Patients with Different Types of Symptom.

\begin{tabular}{|c|c|c|c|c|c|}
\hline NK cell (\%) & $11.78 \pm 2.11$ & $12.40 \pm 3.84$ & $13.11 \pm 3.31$ & $12.98 \pm 4.10$ & 0.9639 \\
\hline $\begin{array}{l}\text { NK cell count } \\
\left(10^{6} / \mathrm{L}\right)\end{array}$ & $\begin{array}{l}182.75 \pm \\
42.66\end{array}$ & $202.50 \pm 50.27$ & $280.67 \pm 98.02$ & $\begin{array}{l}192.50 \pm \\
66.81\end{array}$ & 0.2316 \\
\hline \multicolumn{6}{|l|}{ CT findings } \\
\hline $\begin{array}{l}\text { The total CT } \\
\text { score }\end{array}$ & $7.50 \pm 6.84$ & $9.36 \pm 7.41$ & $9.33 \pm 0.47$ & $6.75 \pm 4.66$ & 0.9029 \\
\hline Left upper lobe & $1.50 \pm 1.66$ & $1.43 \pm 1.76$ & $3.00 \pm 1.41$ & $1.00 \pm 1.22$ & 0.5001 \\
\hline Left lower lobe & $1.50 \pm 1.12$ & $2.57 \pm 1.92$ & $2.00 \pm 0.82$ & $1.50 \pm 0.87$ & 0.5765 \\
\hline Right upper lobe & $1.75 \pm 1.48$ & $1.64 \pm 1.67$ & $0.67 \pm 0.47$ & $2.25 \pm 1.79$ & 0.4994 \\
\hline Right middle lobe & $1.75 \pm 1.79$ & $1.71 \pm 1.75$ & $2.00 \pm 1.63$ & $0.75 \pm 1.30$ & 0.3624 \\
\hline Right lower lobe & $1.00 \pm 1.00$ & $2.00 \pm 1.56$ & $1.67 \pm 0.94$ & $1.25 \pm 1.30$ & 0.6259 \\
\hline
\end{tabular}

Severity of illness

scores

\begin{tabular}{llllll} 
MuLBSTA & $7.75 \pm 2.59$ & $5.36 \pm 4.43$ & $6.00 \pm 2.16$ & $3.25 \pm 1.30$ & 0.4574 \\
\hline CURB-65 & $0.25 \pm 0.43$ & $0.14 \pm 0.35$ & $0.33 \pm 0.47$ & $0.00 \pm 0.00$ & 0.6783 \\
\hline PSI grading & $2.00 \pm 0.71$ & $1.64 \pm 0.72$ & $1.67 \pm 0.47$ & $1.25 \pm 0.43$ & 0.5381 \\
\hline PII & $0.28 \pm 0.25$ & $0.38 \pm 0.31$ & $0.41 \pm 0.07$ & $0.24 \pm 0.17$ & 0.7948
\end{tabular}

COVID-19, Coronavirus Disease 2019; WBC, White blood cell; NEU, Neutrophil; LYM, Lymphocyte; MON, Monocyte; PLT, Platelet; NLR, Neutrophil-to-lymphocyte ratio; PLR, Platelet-to-lymphocyte ratio; SII, Systematic inflammatory index; PCT, Procalcitonin; IL-6, Interleukin-6; CRP, C-reactive protein; ESR, Erythrocyte sedimentation rate; ALT, Alanine aminotransferase; AST, Aspartate aminotransferase; TBIL, total bilirubin; DBIL, Direct bilirubin; ALP, Alkaline phosphatase; GGT, $y$-Glutamyl transpeptidase; LDH, Lactate dehydrogenase; $\mathrm{CK}$, Creatine kinase; $\mathrm{CK}-\mathrm{MB}$, Creatine kinase-MB; a-HBDH, a-Hydroxybutyrate dehydrogenase; BUN, Blood urea nitrogen; $\mathrm{Cr}$, Serum creatinine; eGFR, Estimated Glomerular Filtration Rate; INR, International Normalized Ratio; APTT, Activated partial thromboplastin time; PT, Prothrombin time; PSI, Pneumonia severity index; PII, Pulmonary inflammation index.

\section{Figures}




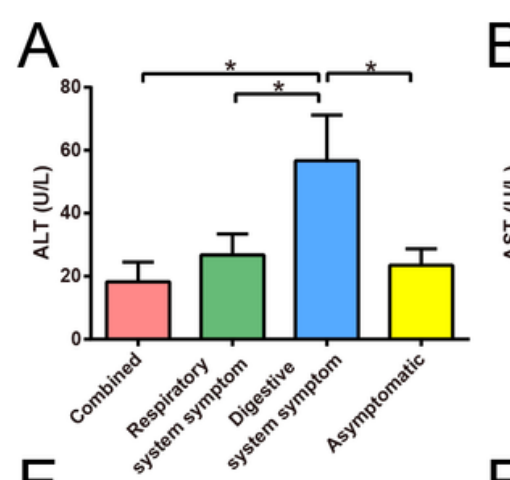

$\mathrm{E}$
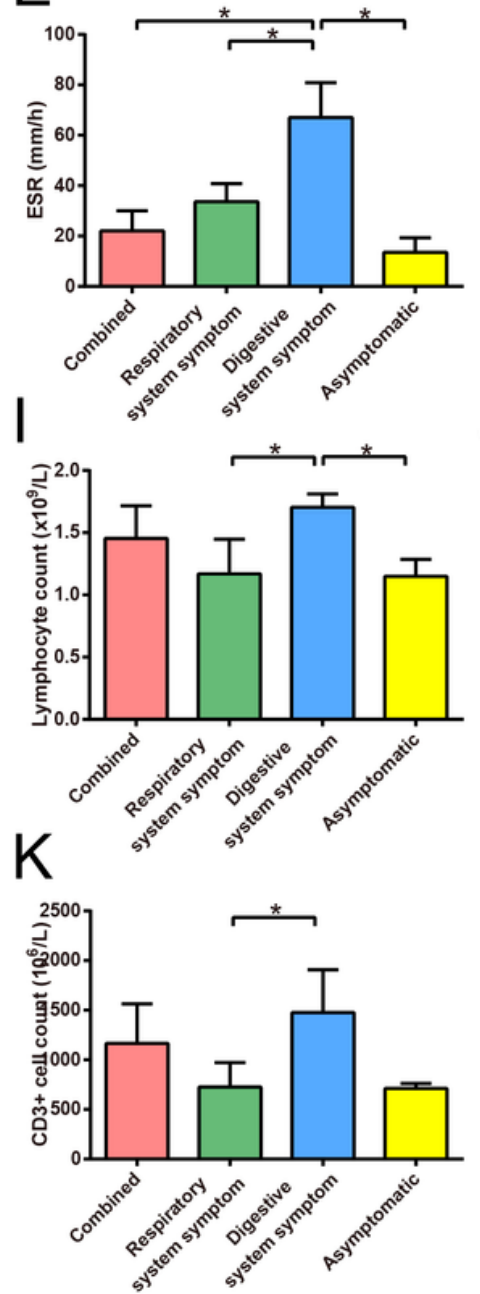

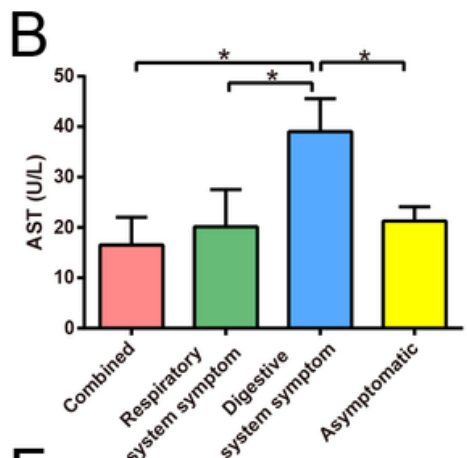

$\mathrm{F}$
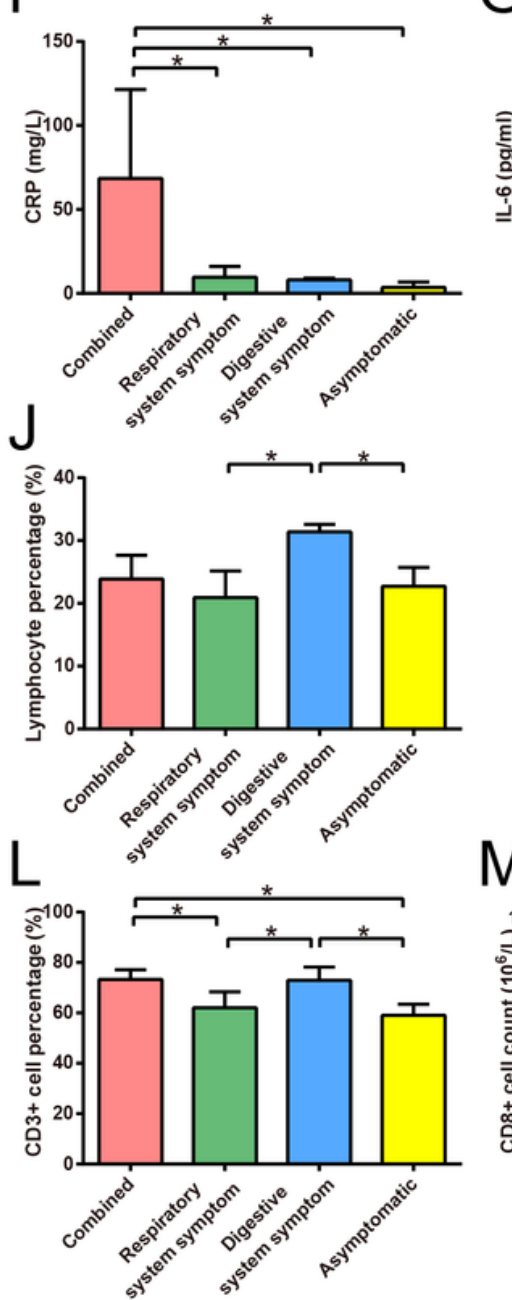

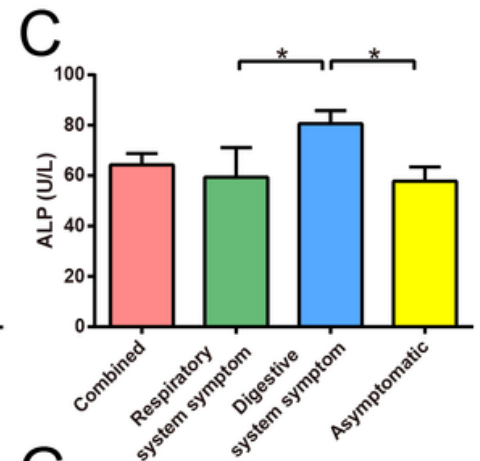

$\mathrm{G}$

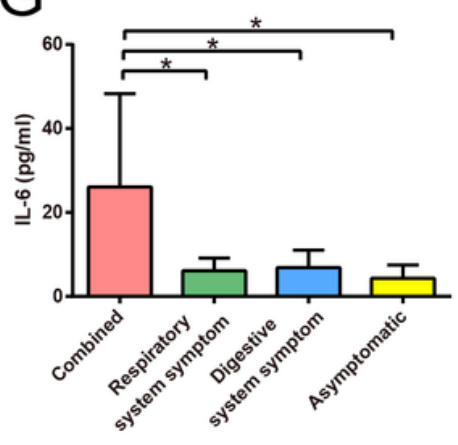

$\mathrm{H}$
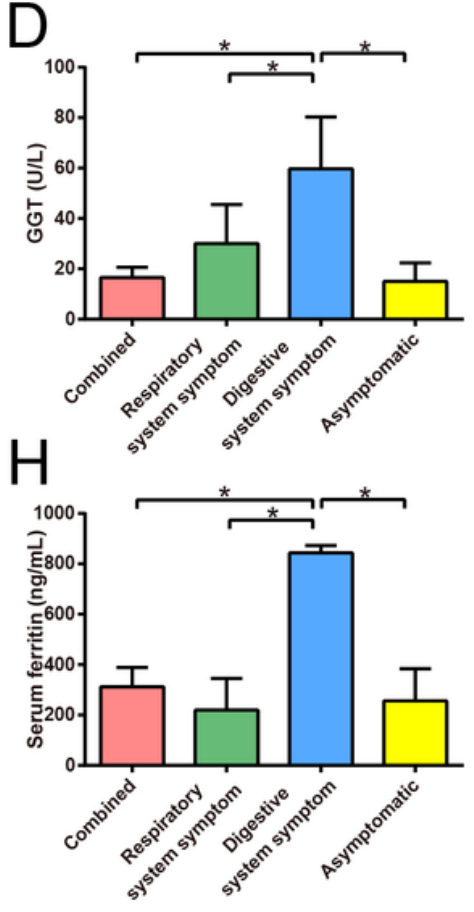

M

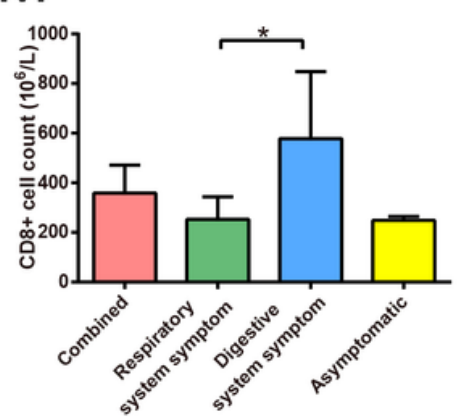

Figure 1

Laboratory examination differences in each group. (A-D) Differences in liver function. (E-H) Differences in infection-related indexes. (I-J) Differences in blood routine test. (K-N) Differences in T lymphocyte subsets. 


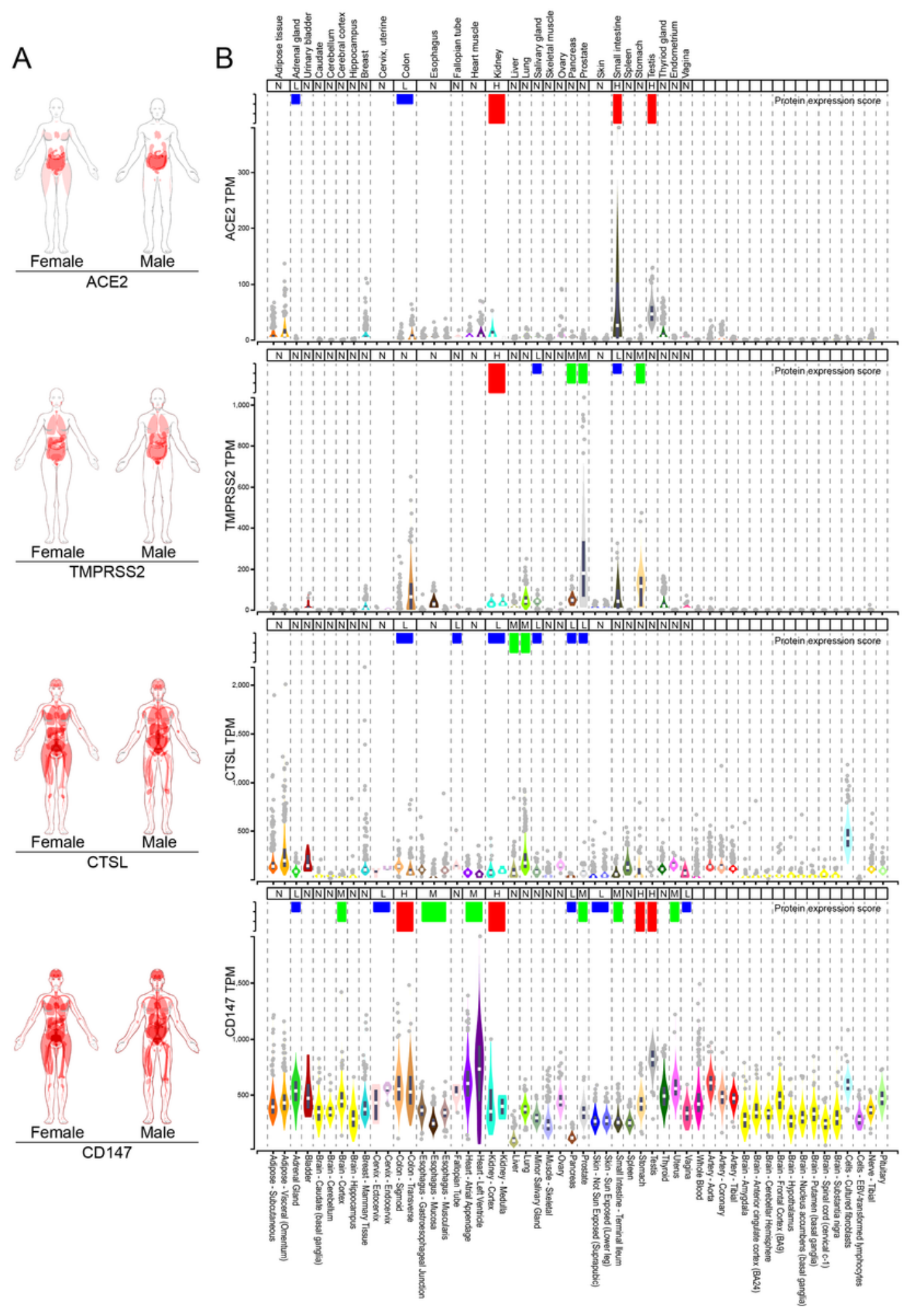

Figure 2

Protein and mRNA expression profiles of binding and endocytosis proteins of COVID-19 in tissue specific organs. 


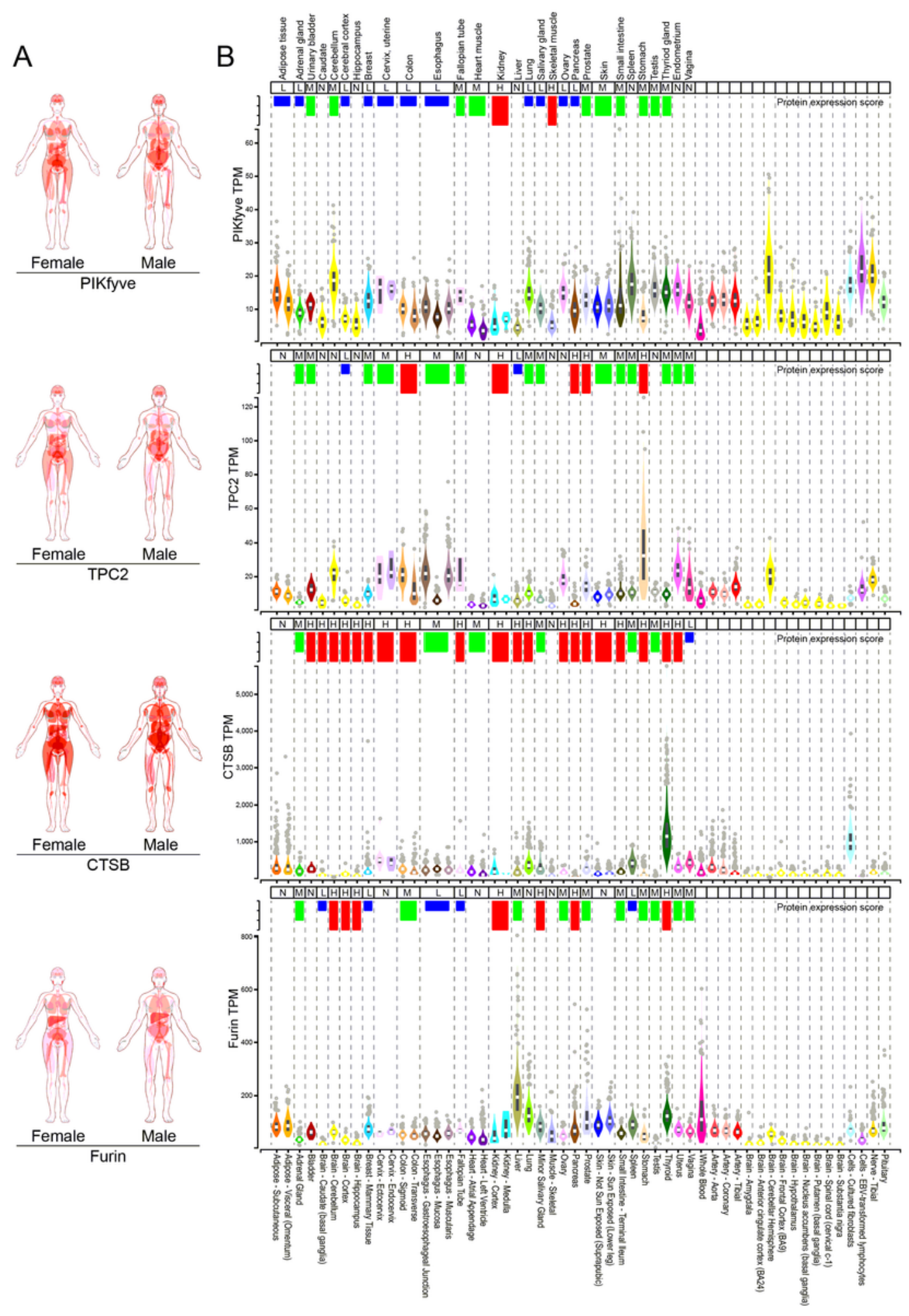

Figure 3

Extensive protein and mRNA expression profiles of binding and endocytosis proteins of COVID-19 in nontissue specific organs.

\section{Supplementary Files}


This is a list of supplementary files associated with this preprint. Click to download.

- SupplementalFigure1.tif

- SupplementalTable3.docx

- SupplementalTable2.docx

- SupplementalTable1.docx 